$\mathrm{Oz}$

$1-1-2006$

\title{
The Bat Signal: Exploring the Relationship Between Justice and Design
}

Bryan Bell

Follow this and additional works at: https://newprairiepress.org/oz

\section{c) (1) $\Theta($}

This work is licensed under a Creative Commons Attribution-Noncommercial-No Derivative Works 4.0 License.

\section{Recommended Citation}

Bell, Bryan (2006) "The Bat Signal: Exploring the Relationship Between Justice and Design," Oz: Vol. 28. https://doi.org/10.4148/2378-5853.1435

This Article is brought to you for free and open access by New Prairie Press. It has been accepted for inclusion in Oz by an authorized administrator of New Prairie Press. For more information, please contact cads@k-state.edu. 


\section{The Bat Signal}

Exploring the Relationship Between Justice and Design

\section{Bryan Bell}

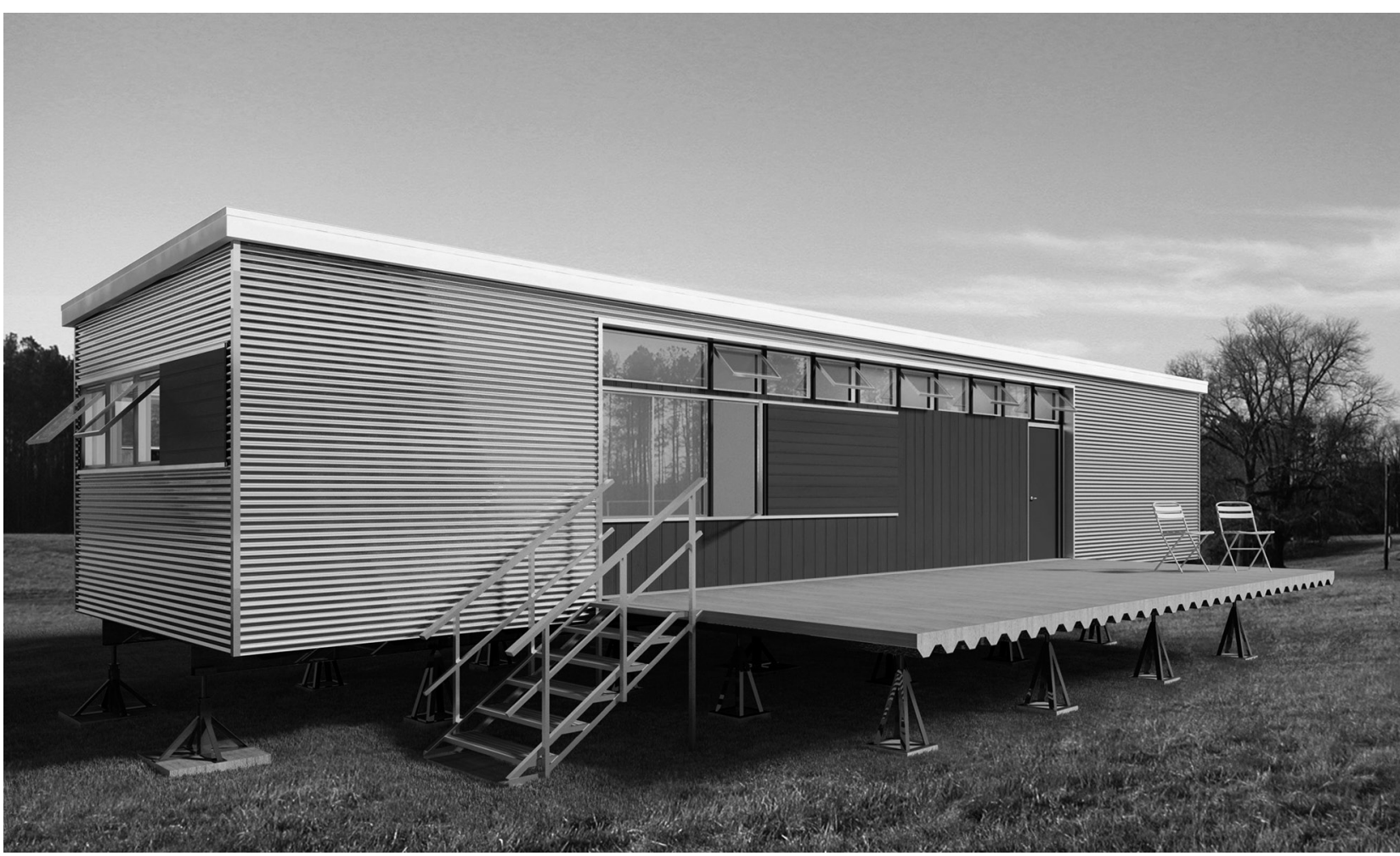

SEED is a network of organizations and individuals dedicated to build and support a culture of civic responsibility and engagement in the built environment and the public realm. We promote and foster public interest architecture, urbanism, and landscapes, which are design and socially progressive, celebrating the idea that design matters and all people can shape their world. The network facilitates communication, evaluation, and knowledge building to support and promote a more relevant role for architecture and design in social, economic, and environmental issues.

\section{Background}

In October of 2005, a group of thirty architects, designers, and other diverse experts of the public interest design movement convened for a roundtable one hundred organizations, design advocates, and social activists, including the Association for Community Design. Their goal was to evaluate the at the Harvard Graduate School of Design. The group represented over both worlds. Called "community-based design," this practice of "trusting the local" is increasingly recognized as the most effective way to sustain the health and longevity of a place.

Architecture firm owner, professor, and past Mayor of Charlottesville, Maurice Cox, one of the organizers, issued the challenge that "While health, safety, and welfare may be promoted as the standard for professional licensure, they should not be the limit of architects' professional roles. We know from experience that people can shape their own world. What results is far superior to anything an outside 'expert' could arbitrarily come up with.”

John Peterson, a firm owner and founder of nonprofit Public Architecture, was one of a number of attendees to propose the establishment of a network for support and communication purposes. Another participant, Reed Kroloff, Dean of the Tulane School of Architecture, suggested that this network could be "the basis of a support system for students and professionals interested in entering this sector." strengthen those roles in communities where they're needed most.

From the initial meeting emerged the Social, Economic, Environmental, Design (SEED) network. The network sees itself as part of a global movement that believes that design can support a community from the ground up. Professionals experienced with process work alongside locals experienced with a place to achieve the best of

\section{The Bat Signal: A Network} That Responds with Help

The operating of the network is being worked out in the hopes that a community could invite SEED members to assist with local challenges, (shining the Bat Signal into the night sky). The focus of the convened meeting would be defined by locals but hope- 
fully addressed through follow-up by collaborations between local experts and non-locals experts.

As a first meeting, by invitation of Tulane, the network met in New Orleans in February 2006 to continue shaping its mission and explores ways to contribute to and learn from the city's recovery effort. Over sixty architects, planners, developers, academics, advocates and artists convened in the Crescent City to explore the process of "re-inhabiting," as some locals call it. Clifton James, head of the local Community Design Center, noted: "We recognize that professionals across the United States want to help, but we need to make sure our solutions are developed here." A local poster for the People's Hurricane Relief Fund quotes a South African slogan: "Nothing about us without us is for us."

Local architect Ray Manning and Reed Kroloff, Dean of the School of Architecture at Tulane University, both members of the Mayor's Bring Back New Orleans Commission, briefed the group on the recovery plan due this summer. "Before the storm, New Orleans was a city in decline, with one third of its population below the poverty line," said Kroloff. "No one wants to recreate those physical conditions, but we hope that everyone who wants to will be able to come back." Only 120,000 people out of pre-Katrina 480,000 currently inhabit in the city.
SEED brought together people from various disciplines that share a commitment to the importance of collaborative design that engages whole communities. One example of this collaboration that has already taken shape in response to these discussions is the Katrina Furniture Project. Conceived by Stephen Goldsmith, Director of the Enterprise Foundation's Frederick P. Rose Architectural Fellowship Program, the project will help re-employ New Orleans residents to create furniture and other useful objects out of material salvaged from the storm's debris. "We want to support local efforts that bring the resilient, creative spirit of local artists and others together as they unite to rebuild their homes," said Goldsmith. "The furniture project expresses our commitment to bringing SEED principles to community development processes at every scale.”

\section{Walk the Walk}

I offer the Florida Migrant Farm worker Housing as and example of the SEED approach in action. Led by Laura Shipman, Shaun Patchell, myself, and many local partners, the purpose of this project is designed to address the shortage of migrant farm worker housing in Florida due to the recent hurricanes.

The hurricane season of 2004 was one of the most active seasons on record as reported by the National Oceanic and Atmospheric Administration. Damage is estimated at forty-five
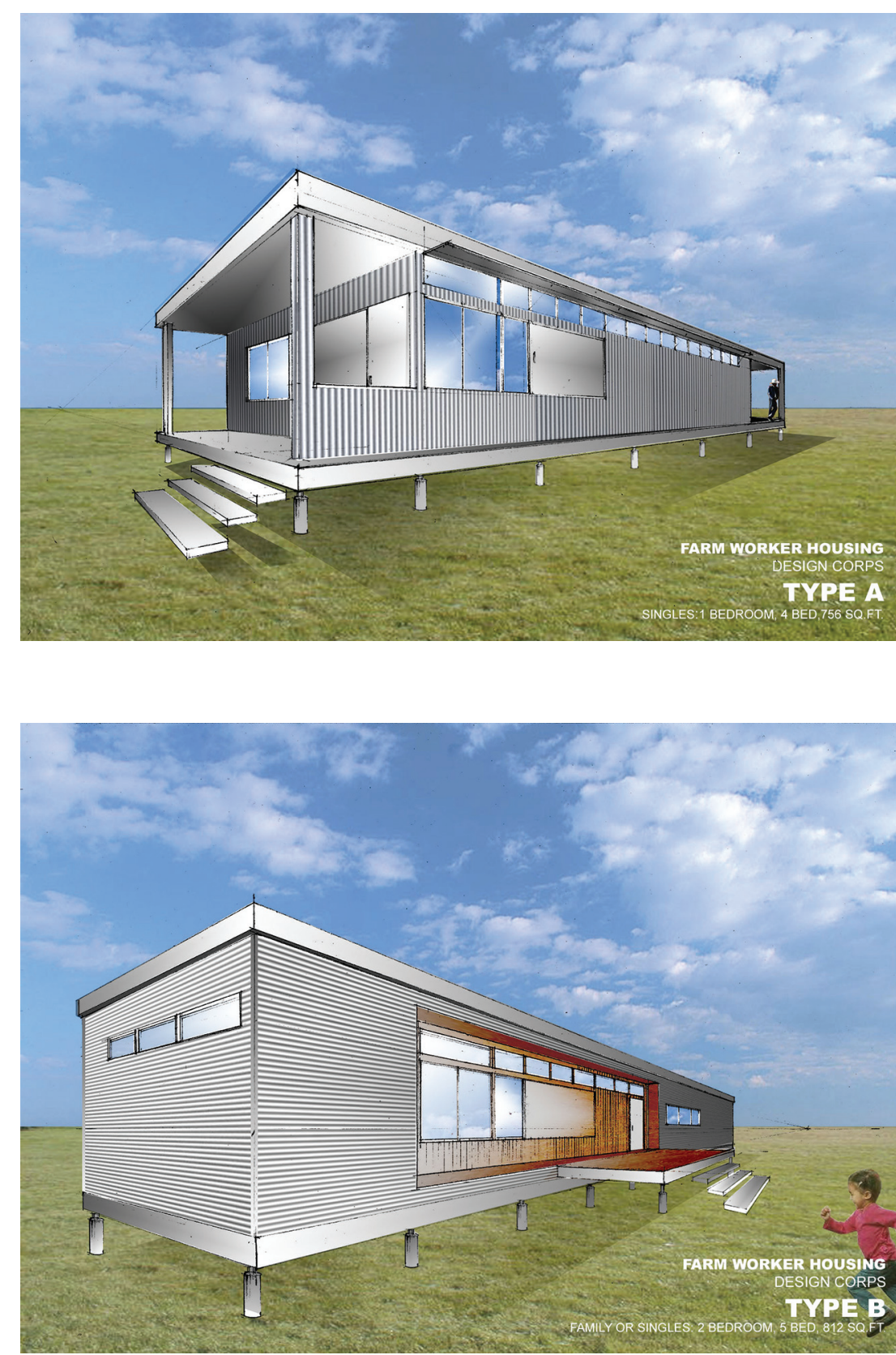

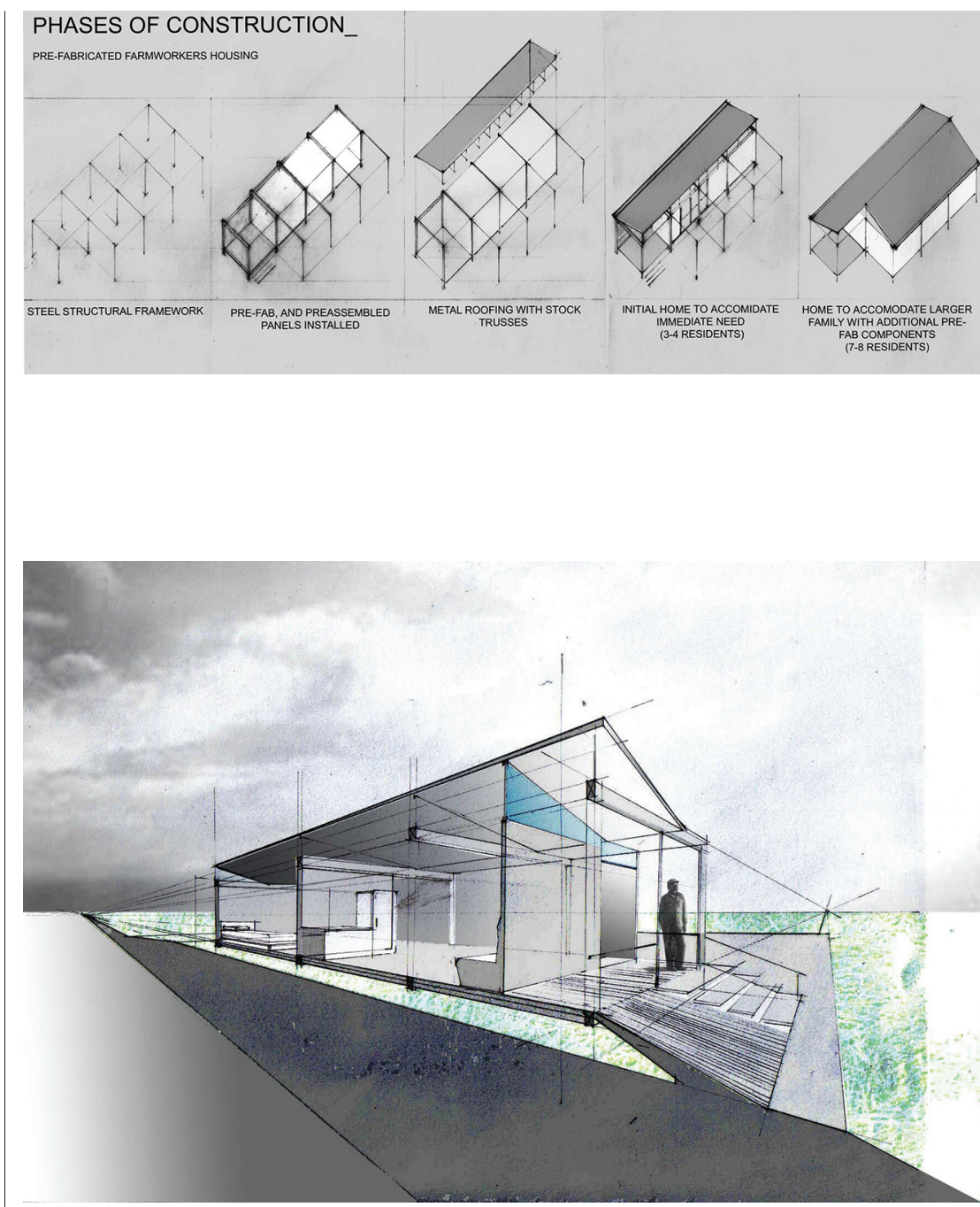

billion dollars. The paths of the most destructive, land-falling hurricanes repeatedly crisscrossed the state of Florida. By November 3, 2004 all sixty-seven counties in the state of Florida had been federally designated as disaster areas.

Responding to the disaster brought on by the recent hurricanes is the greatest challenge facing Central and Southern Florida today. The difficulties are especially complicated for the approximately three hundred thousand migrant farm workers and their families, who help to sustain the agricultural industry throughout Florida. For these families, annual incomes do not exceed ten thousand dollars per year, and affordable housing is either severely limited or restricted to dilapidated mobile homes. This housing is extremely vulnerable to storm damage and the recent hurricanes have destroyed or damaged hundreds of units of farm worker housing exacerbating an already existing shortage. The fourteen counties most severely impacted by the storms, as reported by FEMA, house approximately one-third of all Florida's farm workers. Presently, the three critical problems facing farm workers and their families are: damaged and destroyed housing, over crowding in limited housing available, and limited employment opportunities due to extensive crop damage.

These are of direct and critical impact on the social and economic lives of these workers. We defined four specific responses to these challenges:

\section{Quality Design}

We began with market research into best construction practices and special sensitivity to the individual culture needs and desires of the end users. By including farm workers in the design process, Design Corps has been able to design a product that addresses the highest priorities of the clients. This effectively distributes even the most limited resources to the most valued product. In general, the manufactured housing industry has gained ground in middle and upper income, it is important that the industry continue to develop it's original client base, low-income households, with better products and improved image.

\section{Long-Term Value}

The approach taken was because members of the task force sought not just a short-term emergency response to the crisis, but they sought to use state-funded appropriations to build housing that has long-term equity. Past emergency housing, such as the FEMA model, has provided a short-term solution that becomes poor long-term housing. This is due directly to design choices in construction. The specific charge of the designer was to create housing that would gain in value over a thirty-year life span. Previous specifically designed manufactured housing built in other states has already demonstrated this capacity.

\section{Hurricane Resistance}

One of the unexpected findings after the hurricanes of 2004 was of the hurricane resistance of post-1994 HUD housing. As stated in a letter from Lori E. H. Killinger, Director of Governor's Relations for the Florida Manufactured Housing Association to Mr. Thaddeus Cohen, Secretary of Florida Department of Community Affairs, dated September 13, 2004:

In sum, the Department of Highway Safety and Motor Vehicles findings were clear that: the newer homes, built since HUD changed its building code in 1994, performed (without exception) admirably. It was not uncommon to see several destroyed homes with the newer HUD homes standing alone with only the damage being from flying debris. To further substantiate that finding, after touring the area, Governor Jeb Bush was quoted as saying that the new construction and installation standards for manufactured homes worked. 
In the end, as a matter of construction, there is no valid reason to not consider utilizing manufactured homes as a viable, safe and affordable housing option. In fact, it may be that the best option to provide the citizens of our state and the victims of these horrible storms with permanent, good quality homes.

The assurance bolstered our beliefs that using manufactured housing was a sound approach for farm worker housing recovery. Yet we continue to investigate storm shutter systems and better tie-down systems. And while the environmental issues are not primary to the rapid response needed by this group of users, we are researching the best ways to assure sustainable environment and healthy communities.

\section{Implementation of the \\ Design Solution}

The design process has been completed. Consultations primarily with migrant farm workers and with many others involved in farm worker housing issues such as non-profits, growers, Catholic charities, HUD, and the Department of Health have informed the design process and infused the project with specifications responsive to existing housing problems. The demonstration project, to be manufactured by the summer 2005 will be a model for non-profit organizations and growers as to the possibilities of careful design and manufactured construction. Input from growers and non-profits with experience in operating farm worker housing as well as HUD have led to the funding of a prototype through a grant to the University of Florida.

The plan for the resulting model unit is to be used throughout the state both to respond to the need to replace housing destroyed in the hurricanes and to address the general need for affordable housing for farm workers. Economies of scale will be gained by building a large number of these units, which will help keep the cost down.

Florida is receiving millions of dollars in emergency assistance from the federal government through a variety of programs including twenty million dollars which has been appropriated by the Florida Legislature for farm worker housing above what is regularly available through the programs administered through the Florida Housing Finance Corporation.

While many projects claim to be community based or of community benefit, there is no standard way to evaluate the truth to these claims. In the future the goal is to have a method of evaluating how well a project meets the goals of social, economic and environmental justice through design.
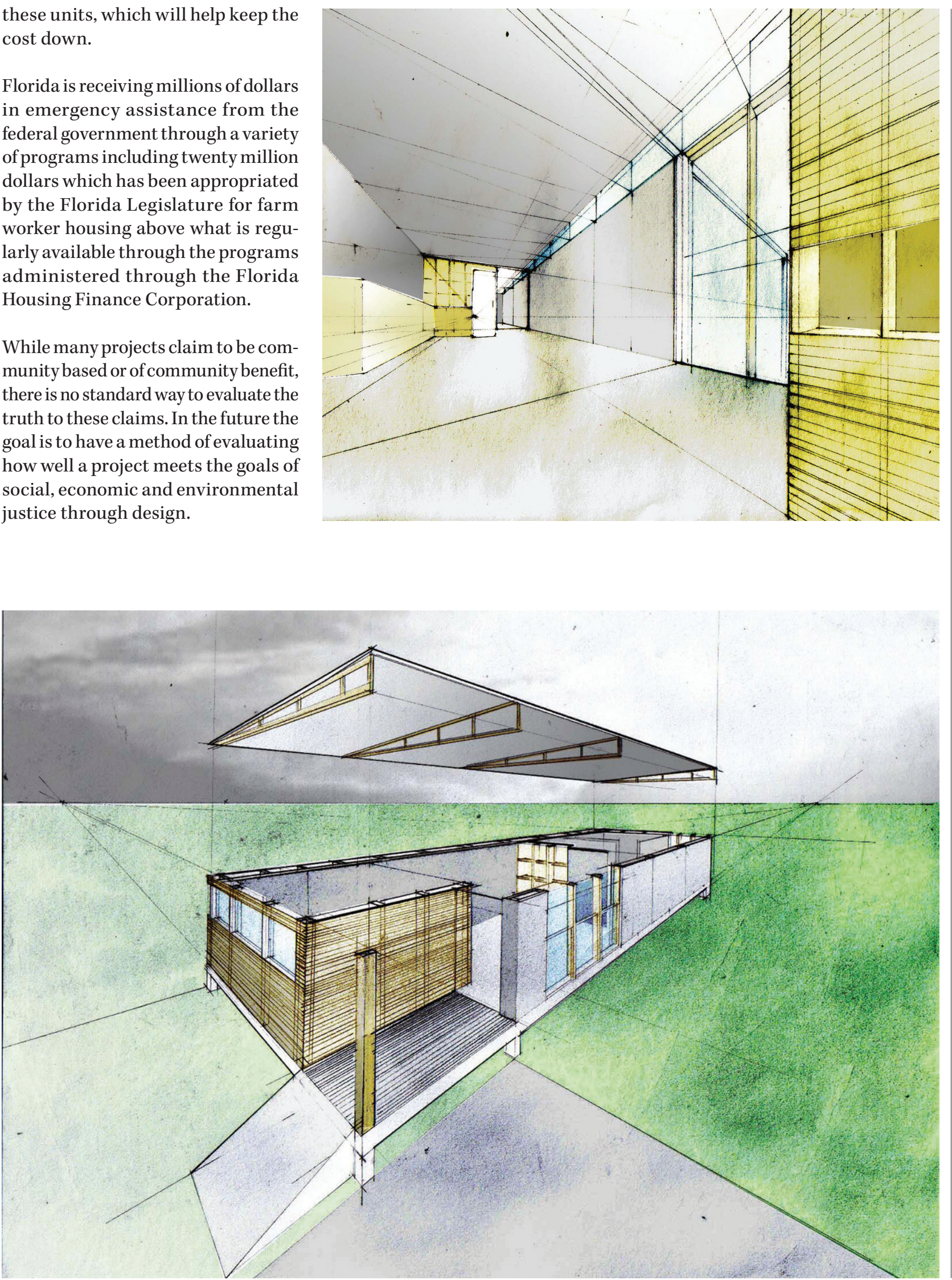